\title{
TELEMEDICINE IN TIMES OF CORONAVIRUS DISEASE-19 AT A TERTIARY CARE GOVERNMENT HOSPITAL IN UTTAR PRADESH, INDIA
}

\author{
ADITY PRIYA ${ }^{1 *}$, KUNWAR VAIBHAV ${ }^{2}$, SALIL KUMAR SRIVASTAVA ${ }^{3}$, VIJAY KUMAR ${ }^{4}$ \\ ${ }^{1}$ Department of Community Medicine, Autonomous State Medical College, Ayodhya, Uttar Pradesh, India. ${ }^{2}$ Department of Psychiatry, \\ Autonomous State Medical College, Ayodhya, Uttar Pradesh, India. ${ }^{3}$ Department of Pharmacology, Autonomous State Medical College \\ Ayodhya, Uttar Pradesh, India. ${ }^{4}$ Department of Plastic Surgery, Autonomous State Medical College, Ayodhya, Uttar Pradesh, India. \\ Email: aditypriya@gmail.com
}

Received: 25 September 2020, Revised and Accepted: 26 October 2020

\section{ABSTRACT}

Objective: The present study aimed to describe the common symptoms and diagnosis for each specialty which can be used in future for expansion of teleconsultation services and implementation of the E Sanjeevani model in health care.

Methods: This is a cross-sectional observational study which comprises the data collected from various specialties over a 4-month period. The telemedicine consultations were given by the consultants of the concerned specialty in adherence to the telemedicine guidelines issued by the government and mostly generic names of the medicine were advised to the patients. The demographic details, chief complaint of the patient, diagnosis, and treatment were recorded.

Results: The total number of calls which was received in 4 months period at the telemedicine center in Government Medical College, Ayodhya, was 4848. Maximum number of calls was attended by the department of obstetrics and gynecology which was 771 (15.9\%). Coronavirus disease (COVID-19) had a substantial and transformative influence on routine clinical practice across the entire clinical continuum in a very short period of time.

Conclusion: The use of telemedicine emerged as a critical tool to improve the provision of health services. The virtual media and other technologies that can be delivered to patients doorsteps need to strengthened. The trailer which telemedicine showed up in times of COVID-19 can definitely produce a good show in days to come with proper communication between the service provider and receiver.

Keywords: Coronavirus disease-19, Telemedicine, Telepathy.

(c) 2020 The Authors. Published by Innovare Academic Sciences Pvt Ltd. This is an open access article under the CC BY license (http://creativecommons. org/licenses/by/4. 0/) DOI: http://dx.doi.org/10.22159/ajpcr.2020.v13i12.39864

\section{INTRODUCTION}

The world was taken up by the novel coronavirus disease (COVID-19) pandemic progressively since its spread from China which affected the global socioeconomic political scene [1]. The health-care system was the one which had to face the major burnt of the situation. While the majority of the resource was diverted to the management of COVID19-related patients, the need was felt to address the concerns for nonCOVID-19 health-related issues [2,3].

With the routine outpatient department (OPD) services being suspended to keep a check on social distancing, the government directed to start teleconsultations for the patients. The Ministry of Health and Family Welfare in March 2020 released the guidelines for telemedicine to aid the establishments to implement it with proper framework [4]. Telemedicine has been defined by the WHO as the remote delivery of health-care services by health-care professionals using information and communication technologies for the exchange of valid information for the diagnosis, treatment, and prevention of disease and injuries, research and evaluation, and for the continuing education of healthcare providers, all in the interests of advancing the health of individuals and their communities [5].

Telemedicine emerged as an effective bridge between the health professionals and the patients considering the importance of social distancing at this time of national crisis. The purpose of this study is to describe the common symptoms and diagnosis for each specialty which can be used in future for expansion of teleconsultation services and implementation of the E Sanjeevani model in health care.

\section{METHODS}

This is a cross-sectional observational study which comprises the data collected from various specialties over a 4-month period from May 1, 2020, to August 31,2020, of the telemedicine center of Government Medical College, Ayodhaya, Uttar Pradesh. The calls were attended by the concerned departments from 8 am to $4 \mathrm{pm}$ on all days except Sundays. The advertisement was provided in local newspapers thrice since its inception. Banners with the numbers were displayed at public places and other government health institutions in the district. WhatsApp (mobile application) was also used to circulate the numbers to general public. The numbers and smartphones were allotted to each department with facility of video calls and two numbers were given for common helpline in case of no response or connection errors in the allotted numbers. Patient's consent was taken before starting the teleconsultation. The telemedicine consultations were given by the consultants of the concerned specialty in adherence to the telemedicine guidelines issued by the government and mostly generic names of the medicine were advised to the patients. Those patients who required physical examination were given appointment as and when required after proper triage. Follow-up calls were also encouraged to make the system more efficient and satisfactory for the patients. The telephonic conversations between the patient and the doctor were supplemented by the transfer of photographic-videographic data and investigation records through internet-based services like WhatsApp. The demographic details, chief complaint of the patient, diagnosis, and treatment were saved in Microsoft Excel sheets and compiled daily and on weekly basis for all the departments and the common helpline number. The cumulative data and frequency distribution for each department were recorded. 


\section{RESULTS}

The total number of calls which was received in 4 months (from May 1,2020 , to August 31, 2020) period at the telemedicine center in Government Medical College, Ayodhya, was 4848 . The specialty wise distribution is illustrated in Fig. 1. A total of 4520 (111 calls had some missing variables and 217 calls were received on common helpline which was diverted to other departments as and when required) calls were analyzed for demographic profile of the patients. Table 1 describes about the demographic profile of the patients by/for whom calls were made.

\section{DISCUSSION}

\section{Dentistry}

The total number of calls received by the department of dentistry was $503(10.38 \%)$ which states that almost one-tenth of the total calls was received by them. The most common symptoms and diagnosis which was addressed by them was that of tooth pain (38.3\%), bleeding/ swelling in gums (23.4\%) (gingivitis), tingling sensation while having cold beverages/water (22\%) (dental hypersensitivity), and other symptoms and diagnosis and follow-up calls comprised $16.3 \%$ of the calls. Many patients seek teleconsultation for dental problems as it is considered as a high-risk specialty in COVID-19 times and both the dentist and patients avoid close contact. Most of the dental OPD services remained closed in both government and private set up which may be considered as another reason for increased number of teleconsultations for dental problems. The drawback of telemedicine implementation in dentistry is that many treatments require interventions and cannot be solely managed by medicines. But again here, it can be emphasized that

Table 1: Demographic profile of the patients by/for whom calls were made

\begin{tabular}{ll}
\hline Variables & Frequency $(\mathbf{n = 4 5 2 0 )}(\mathbf{\%})$ \\
\hline Age & \\
$<15$ years & $446(9.9)$ \\
15-64 years & $3867(85.6)$ \\
$\quad 65$ years and above & $207(4.6)$ \\
Sex & \\
Male & $2535(56.1)$ \\
Female & $1985(43.9)$ \\
District & \\
Ayodhya & $3278(72.52)$ \\
Other districts in UP & $1186(26.24)$ \\
Outside UP & $56(1.24)$ \\
\hline
\end{tabular}

telemedicine can be used for proper triage and appointment for elective interventions in the patients.

Ear, nose, and throat (ENT) (otorhinolaryngology) - The total calls attended were 361 (7.45\%). The chief complaints reported to ENT were queries regarding COVID-19 testing and symptoms. The telemedicine data clearly propel us to reach out more to communities with ENT screening using advanced telemedicine tools. Literature search revealed about ENTraview, a store-and-forward telemedicine device that integrates a camera-enabled smartphone with an otoscope [6]. Community otology screenings were conducted to triage otology patients and provide them with specialized ENT care at a tertiary hospital using this device [6]. Being a specialty of high risk of exposure, telemedicine can be exploited for screening and triage of patients not only in COVID-19 times but also even after this phase and the services can be made available to hard to reach patients.

\section{Medicine}

A total of $427(8.8 \%)$ calls were attended by the department of medicine. Surprisingly, the overall calls were less compared to regular OPDs where major bulk of the OPD is managed by them. This may partly be explained because of the fact that FLU OPD was functional in the hospital and patients with complain of fever, sore throat, and shortness of breath were managed there itself with COVID-19 testing being provided to those who required it. Moreover, patients of chronic diseases who were stable would have preferred to continue with the same medication and minimal calls would have been made by them. Telemedicine can be very well used in patients of chronic diseases for follow-up and monitoring of patients who are otherwise stable, especially in times of such national crisis where physical accessibility was difficult and unsafe. Diabetes care has been provided by a medical institution in lockdown period which can be replicated for the benefit of diabetic patients [7].Similar teleconsultation can be promoted for other chronic diseases such as asthma and hypertension.

\section{Obstetrics and gynecology}

Maximum number of calls was attended by the department of obstetrics and gynecology which was 771 (15.9\%). The antenatal calls were made mostly by the patients who were already registered in the hospital.

In India, the G Protein-Coupled Receptors advice screening of antenatal patients using the checklist tool on telephone itself and recommend the testing of women from hotspot districts, even if asymptomatic, when presenting in labor or likely to deliver in next 5 days [8]. Telemedicine was utilized for reports and investigations review by the doctors. Those who required immediate attention were referred to the district hospital

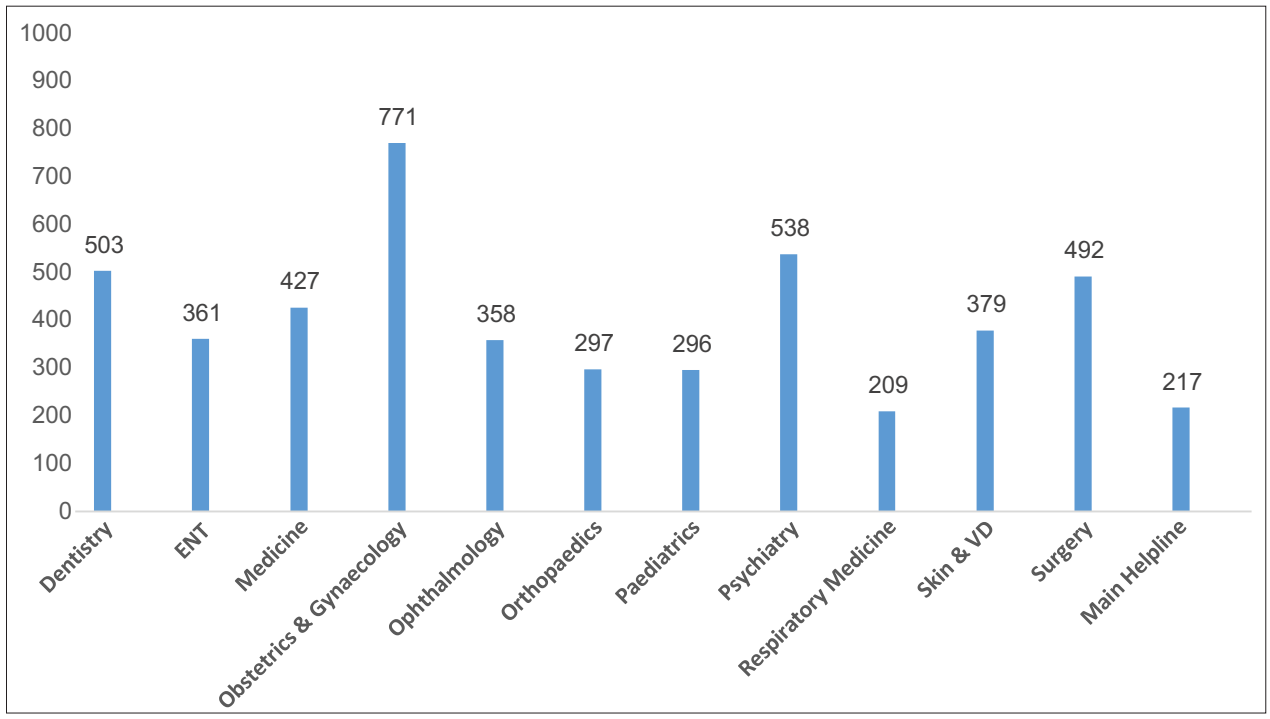

Figure 1: Frequency distribution of calls attended in each specialty 
where antenatal care high-risk cases were attended during lockdown too. Counseling of patients was also done through telemedicine for mental health well-being as maternal mental ill health is known to be harmful for both the mother and the baby. Postpartum care for COVID-19 patients who had delivered in this hospital also utilized telemedicine for verbal assessment of any symptoms in mother or the baby. An alarming note is the conversion of a tertiary hospital into a COVID hospital which was a referral center for many emergency obstetric care patients. There is a dire need for patient educational campaigns and the encouragement of public health officials, media, and local physicians to address patients' apprehension, and to convey that it is safe to come to the hospital for emergency obstetric care, which if untreated, has a higher morbidity and mortality rate compared with COVID-19 [9]

\section{Ophthalmology}

The department attended a total of 358 (7.38\%) calls in this period. The main symptoms which the patients presented were that of itching, eye ache, and swelling and diminution of vision and the common diagnosis was refractive errors, chronic allergic conjunctivitis, and stye. Images and videos were used on WhatsApp to make diagnosis and prescribe medicines. Incorporation of tele-ophthalmology tools can be very useful in the future to reach out to underserved areas. Tele-ophthalmology can also be used for triage and providing prior appointments to the patients who have to undergo elective surgeries. Literature search revealed that the use of diagnostic tools like the glued IOL microscope [10], DIYretcam [11], and Trash to Treasure Retcam [12] can be very efficient models [13]

\section{Orthopedics}

A total of 297 (6.13\%) calls were received by the department. Most of the calls were regarding joint pain, follow-up calls of post-operative cases and query regarding trauma cases management. The limitation to the proper usage of tele-orthopedics was that of unavailability of $\mathrm{X}$-ray reports at time of teleconsultation. The previous studies have revealed that the response rate and overall patient satisfaction rates to telemedicine in orthopedics are high [14]. It can definitely be used for follow-up chronic cases for whom the patients records and diagnosis are available with the doctor.

\section{Pediatrics}

A total of 296 (6.1\%) calls were attended by the department of pediatrics. Many calls came from the parents regarding immunization services. Other common symptoms for which teleconsultation was done were diarrhea, abdominal pain, and cough and cold. Teleconsultation is very challenging in pediatrics, especially for under five children without physical examination. Video and images were used for assessment in few cases. Telemedicine in pediatrics may be of limited use for doctorpatient communication but indirect use in terms of consultation with a superspecialist can be of great use for underserved communities in the years to come. Models of care include connecting community and rural health care institutions to perinatal and neonatal specialists of a tertiary care hospital for general advice or assistance during emergencies [15].

\section{Psychiatry}

Psychiatric teleconsultations were done for 538 (11.1\%) patients. Most of the patients were counseled and those who needed immediate attention were referred for in-person consultation. Psychiatry is one field where the legal implications of prescribing medication are very critical. Any narcotic and psychotropic substance listed in the Narcotic Drugs and Psychotropic Substances Act, 1985 comes under the prohibited list. Tele-counseling was provided by the team for followup patients and patients who were worried about the pandemic. It was also utilized for communication with the COVID-19 inpatients for their mental health assessment and was managed accordingly. Telepsychiatric after care clinic for continuity of care of already registered patients with psychiatric disorders has been used by a neuropsychiatric hospital and higher acceptability, feasibility, and possible clinical effectiveness have been reported by them [16].

\section{Respiratory medicine}

Respiratory medicine department catered to 209 (4.31) calls during this 4-month period. The majority of calls were for symptoms of cough and cold and follow-up calls by tuberculosis patients. The patients for whom physical examination or testing for COVID-19 was needed were called in the flu OPD of the hospital. Counseling and awareness were also done for respiratory etiquettes, usage of mask, and social distancing. Availability of X-ray images and investigation reports can make this teleconsultation more robust. The need for physical examination, especially in LRTI (lower respiratory tract infections) patients, is still a major challenge and hence doctor-to-doctor communication will be very useful for communities living in remote areas. Literature search brought to light usage of web-based "store-and-forward" telemedicine service to optimize MDR-TB patient care in Australia [17].

\section{Skin and VD}

A total of 379 (7.82\%) calls were attended by the department of skin and VD. Patients of tinea, urticaria, and allergic conditions constituted the majority of calls. WhatsApp platform for transfer of images for the purpose of making diagnosis was utilized by them. Dermatology emerged as one field where lot of telemedicine services has been used in times of COVID-19. An article with the title "The COVID-19 Outbreak: A Game-Changer in Reinforcing the Use of Telemedicine in Dermatology?" provides an insight into teledermatology [18].

\section{Surgery}

The department of surgery attended $492(10.15 \%)$ calls. The spectrum of patients ranged from those seeking advice on elective surgeries, follow-up of post-operative cases and also patients with acute symptoms of abdominal pain and genitourinary complains. Pre-surgery consultation and post-operative care in stable patients can utilize telemedicine to its best and also reduce the out-of-pocket expenditure of the patient in travelling and other logistics. A study by Murphy et al. assessed the use of post-operative images sent by patients for wound healing, compared to face-to-face post-operative consultations. No difference was experienced in the quality of care between the two methods $[19,20]$.

Calls attended on the common helpline number were mostly regarding query for COVID-19 testing and other specific calls for any specialty were referred to the concerned departments. Helpline number was a boon for connectivity issues on other numbers in which case the patients called up at the helpline number.

\section{CONCLUSION}

Telemedicine was never a center stage player before COVID-19 in India. It provided opportunity to explore the practical implications and challenges for implementation of telemedicine in near future. The legal implications of telemedicine need to be taken care of and proper guidelines issued to safeguard the doctors. This article's finding can definitely provide a roadmap to enhance and allocate the resources in the right direction. The challenges of patient satisfaction and connectivity issues, especially in underserved areas, need to be addressed. This platform can without doubt be expanded for doctor-to-doctor communication over and above the doctor-patient consultation. The virtual media and other technologies that can be delivered to patients doorsteps need to strengthened. The trailer which telemedicine showed up in times of COVID-19 can definitely produce a good show in days to come with proper communication between the service provider and receiver.

\section{AUTHORS' CONTRIBUTIONS}

All authors made substantial contributions to conception and design, acquisition of data, and interpretation of data.

\section{CONFLICTS OF INTEREST}

There are no conflicts of interest. 


\section{AUTHORS' FUNDING}

No fund.

\section{REFERENCES}

1. Chandna VB, Patil SM, Shirahatti PS, Sujay S, Tejaswini M, Ranganatha LV, et al. The current status and perspectives for the emerging pandemic: COVID-19. Int J Pharm Pharm Sci 2020;12:1-10.

2. Hangargekar CB, Quazi RS, Joshi AA. A review on COVID-19-a global battle between life and death. Int J Curr Pharm Res 2020;12:19-24.

3. Singh M, Nagpal M, Singh V, Sharma A, Dhingra GA, Maman P, et al. COVID-19: Epidemiology, pathogenicity and global updates. Int J App Pharm 2020;12:16-28.

4. Telemedicine Practice Guidelines. Available from: https://www.mohfw. gov.in/pdf/Telemedicine.pdf. [Last accessed on 2020 May 25]

5. WHO Telemedicine: Opportunities and Developments in Member States: Report on the Second Global Survey on eHealth; 2009. Available from: https://www.who.int/goe/publications/goe_telemedicine_2010. pdf. [Last accessed on 2020 May 24]

6. Gupta N, Baghotia KS, Rabha M, Sachdeva S, Sahai G, Bhatnagar K, et al. Comprehensive community screening of otological patients by trained technicians using a telemedicine device: An efficient and costeffective way to triage patients with ear diseases. Ear Nose Throat J 2020. Doi: $10.1177 / 0145561320950992$.

7. Joshi R, Atal S, Fatima Z, Balakrishnan S, Sharma S, Joshi A. Diabetes care during COVID-19 lockdown at a tertiary care centre in India. Diabetes Res Clin Pract 2020;166:108316.

8. Gandhi A, Ganatra A, Tank P. FOGSI GCPR on Pregnancy with COVID-19 Infection Version 2. Federation of Obstetric and Gynaecological Societies of India; 2020. Available from: http://www. fogsi.org/fogsi-gcpr-on-pregnancy-with-covid-19-infection-version-2. [Last accessed on 2020 Sep 05].
9. Kumari V, Mehta K, Choudhary R. COVID-19 outbreak and decreased hospitalisation of pregnant women in labour. Lancet Glob Health 2020;8:e1116-7.

10. Akkara JD, Kuriakose A. Commentary: The glued intraocular lens smartphone microscope. Indian J Ophthalmol 2019;67:1692.

11. Raju B, Raju NS, Akkara JD, Pathengay A. Do it yourself smartphone fundus camera-DIYretCAM. Indian J Ophthalmol 2016;64:663-7.

12. Chandrakanth P, Ravichandran R, Nischal N, Subhashini M. Trash to treasure Retcam. Indian J Ophthalmol 2019;67:541-4

13. Akkara JD, Kuriakose A. Commentary: Gamifying teleconsultation during COVID-19 lockdown. Indian J Ophthalmol 2020;68:1013-4

14. Kumar S, Kumar A, Kumar M, Kumar A, Arora R, Sehrawat R. Feasibility of telemedicine in maintaining follow-up of orthopaedic patients and their satisfaction: A preliminary study. J Clin Orthop Trauma 2020;11:S704-10.

15. Garingo A, Friedlich P, Tesoriero L, Patil S, Jackson P, Seri I. The use of mobile robotic telemedicine technology in the neonatal intensive care unit. J Perinatol 2012;32:55-63.

16. Das S, Manjunatha N, Kumar CN, Math SB, Thirthalli J. Telepsychiatric after care clinic for the continuity of care: A pilot study from an academic hospital. Asian J Psychiatr 2020;48:101886.

17. Huang GK, Pawape G, Taune M, Hiasihri S, Ustero P, O'Brien DP, et al. Telemedicine in resource-limited settings to optimize care for multidrug-resistant tuberculosis. Front Public Health 2019;7:222.

18. Hemdani R, Rathod D, Bhargava S, Goldust M, Singh AK. The COVID-19 outbreak: A game-changer in reinforcing the use of telemedicine in dermatology? Skin Med 2020;18:187-8.

19. Murphy RX, Bain MA, Wasser TE, Wilson E, Okunski WJ. The reliability of digital imaging in the remote assessment of wounds: Defining a standard. Ann Plast Surg 2006;56:431-6.

20. Gillman-Wells CC, Sankar TK, Vadodaria S. COVID-19 reducing the risks: Telemedicine is the new norm for surgical consultations and communications. Aesthetic Plast Surg 2020;10:1-6. 